\title{
MEMÓRIA, EDUCAÇÃO E TRABALHO NO PROCESSO DE REPRODUÇÃO DA SOCIEDADE DO CAPITAL
}

\author{
José Rubens Mascarenhas de Almeida* \\ Ana Elizabeth Santos Alves**
}

\section{RESUMO}

Este artigo enfoca, como seu próprio título espelha, a relação simbiótica entre memória, educação e trabalho no processo de reprodução da sociedade contemporânea. Assim, para responder a questões que se põem na ordem do dia (como se relacionam trabalho e educação no sistema do capital? Como o saber construído adentra, de fato, o campo da educação formal? Como educação, memória e ideologia se intercalam nesse processo?), seus autores recorrem a um enfoque ontológico do trabalho, relacionando este à educação esta entendida como instrumento reprodutivo da lógica do capital, mas não só -, entendendo tal relação como mediada pelos instrumentos da memória e da ideologia que permeiam as práticas sociais.

Palavras-chave: Trabalho e Educação; Memória e Ideologia; produção/reprodução do capital.

\section{MEMORY, EDUCATION AND WORK IN PROCESS CAPITAL SOCIETY REPRODUCTION}

\begin{abstract}
This article takes as its title reflects, the symbiotic relationship between memory, education and work in the reproduction process of contemporary society. So, to answer the questions that are put on the agenda (how they relate to work and education in the capital system? How knowledge constructed enters, in fact, the field of formal education? How education, memory and ideology are inserted in the process ?), the authors resort to an ontological approach to work, relating this to education - this understood as reproductive instrument of the logic of capital, but not only - understanding this relationship as mediated by the instruments of memory and ideology permeating social practices .
\end{abstract}

Keywords: Work and Education; Memory and Ideology; production/reproduction of capital.

A discussão sobre a relação trabalho e educação na formação capitalista inscreve outras correlatas, como a da memória e ideologia. Como a relação trabalho/educação trata, ao mesmo tempo, dos processos de produção e reprodução capitalistas, sua interconexão com a questão da ideologia - e da memória como parte constitutiva dessa relação -, aqui nos propomos abordar, nas limitações próprias da natureza deste ensaio, a relação entre trabalho, educação e memória na sociedade capitalista.

Para entender a questão da educação, recorremos a um enfoque ontológico acerca do trabalho, relacionando-o a esta, por sua vez entendida como instrumento reprodutivo da lógica do capital. Quanto à categoria memória, problematizada nas experiências do passado, rememorada por meio das relações cotidianas vividas na rotina da nova sociedade 
do capital, é concebida como construto social, o que implica entendê-la como permeada de práticas sociais ideologizadas, visto que produzidas e reproduzidas no seio de determinada formação social e regidas por, também determinadas, relações sociais. O pressuposto é que o fazer social adquire formas ideológicas traduzidas, também, como memórias. Assim, buscamos questionar: como se relacionam trabalho e educação no sistema do capital? Como o saber construído adentra, de fato, o campo da educação formal? Como educação, memória e ideologia se intercalam? Como a memória se faz presente nos instrumentos didáticos, nas relações estabelecidas nessa esfera, nos saberes constituídos nas relações formais e informais, seja dentro de uma concepção e organização curricular ou de uma instituição de trabalho?

Enquanto conceito, Educação foi historicamente construído a partir da própria constituição da sociedade - paralelamente à composição de grupos humanos organizados , articulada às transformações do processo de produção social da existência humana. É observável a dimensão educativa no desenvolvimento de habilidades e conhecimentos que geraram, historicamente, coletivas formas de agir entre crianças, jovens e adultos.

O processo educacional inicia-se com a lida de homens e mulheres com a natureza e, à medida que adquirem experiência segundo determinada realidade prática, socializam tal educação conforme os modos de viver e de pensar do grupo. Isso mostra que o fenômeno educativo é próprio dos seres humanos e, para compreendermos a sua natureza, necessário se faz abarcar sua sociabilidade por meio do trabalho. Nesse sentido, afirma-se que o processo de trabalho é algo a-histórico, por perpassar toda e qualquer sociedade em qualquer tempo. Como afirma Marx, "o trabalho é um processo entre o homem e a Natureza, um processo em que o homem, por sua própria ação, media, regula e controla seu metabolismo com a Natureza" (1983, p. 149). Na concepção marxiana, e que aqui tomamos como parâmetro, o trabalho é o elemento determinante da própria natureza humana.

Em sua dimensão natural, os seres humanos, diferentemente dos animais comandados por instintos -, pautam-se na necessidade de produzir a sua própria existência com relativa autonomia, partindo da sua vontade e consciência, segundo escolhas e iniciativas próprias. E, desse processo de transformação da natureza como meio de produção de subsistência, provém o ato de trabalhar, tendo a educação aí inserida. Em outras palavras, a "educação é uma exigência do e para o processo de trabalho" (Saviani, 2003, p.12).

A forma como homens e mulheres se fazem durante toda a vida é o resultado de um longo processo de aprendizagem, acumulando experiências e habilidades num contexto social apropriado, a exemplo do uso da linguagem e do ato de trabalhar, conforme um plano e um objetivo. Esse processo acontece de diferentes formas e em diferentes espaços de aprendizagem presentes no decorrer da história, como a família, a rua, a igreja, o trabalho e a escola, em permanente movimento de transitoriedade (Manacorda, 2007).

Ao refletir acerca da educação, é fundamental estabelecer uma análise vinculada ao trabalho, conforme observa Sader: "digam-me onde está o trabalho em um tipo de sociedade e eu te direi onde está a educação" (2005, p. 17). Seguindo esse preceito, ao retrocedermos na história podemos observar, em conformidade com o desenvolvimento produtivo, social e político, a relação educação/trabalho como tendo afinidade de identidade, sendo elementos fundamentais na articulação do indivíduo na sociedade. $\mathrm{Na}$ necessidade humana da produção coletiva de sua existência está o trabalho e, no interior desse processo, a educação nas condições gerais da produção/reprodução social (Saviani, 2007). Se o trabalho está ligado às necessidades humanas e às condições materiais e políticas de cada momento histórico, a educação acompanha esse processo, compreendida 
como uma das maneiras com que as pessoas socializam um saber coletivamente construído, passado através das gerações, guardado pela memória, que mantém o passado, dinâmico que é, em permanente reconstrução.

Paradoxalmente, ao mesmo tempo em que a educação assume um papel libertador do homem, é também a sua alienação, produzindo sua desumanização, principalmente na divisão social do trabalho industrial, quando o trabalhador reconhece o produto de seu labor como algo estranho à sociabilidade do seu fazer. Alienado, o trabalho constitui-se uma forma "estranhada" ao trabalhador sob a determinação do capital, uma vez que produz e reproduz não apenas mercadoria; produz-se e reproduz-se a si mesmo como trabalhador socialmente determinado e alienado (Marx, 1985). Nesse sentido, as práticas sociais produzidas pela sociedade do capital, o que impõe dizer de relações de trabalho alienadas, não poderia projetar práticas educacionais que não reprodutoras de sua lógica (valores, concepções, fazeres, funcionalidade sistêmica...). Os processos sociais de produção/reprodução capitalistas estão simbioticamente relacionados com 0 fazer educacional e seu produto. Segundo Mészáros,

A educação institucionalizada, especialmente nos últimos 150 anos, serviu - no seu todo - ao propósito de não só fornecer os conhecimentos e o pessoal necessário à máquina produtiva em expansão do sistema do capital, como também gerar e transmitir um quadro de valores que legitima os interesses dominantes [...]. A própria História teve de ser totalmente adulterada, e de fato frequente e grosseiramente falsificada para esse propósito (2008, pp. 35-36).

Sob as relações capitalistas, todas as demais conexões são levadas a tomar forma e semelhança com a lógica mercantil - e mercantilista - do capital. Com a educação não é diferente. As possibilidades de rompimento com a lógica do capital são parcas e, inexoravelmente, têm que estar subordinadas à ruptura estrutural das relações de produção. Como afirma, ainda, Mészáros,

[...] a educação formal não é a força ideologicamente primária que consolida o sistema do capital; tampouco ela é capaz de, per si só, fornecer uma alternativa emancipadora radical. Uma das funções principais da educação formal nas nossas sociedades é produzir tanta conformidade ou "consenso" quanto for capaz, a partir de dentro, ou por meio dos seus próprios limites institucionalizados e legalmente sancionados. [..] É por isso que, também no âmbito educacional, as soluções "não podem ser formais; elas devem ser essenciais". Em outras palavras, elas devem abarcar a totalidade das práticas educacionais da sociedade estabelecida (2008, p. 45).

Quando ressaltamos as possibilidades de ruptura através da educação e seu sistema, levamos em conta as lutas sociais resultantes das contradições de classe. Dialeticamente nos posicionando, cremos que a educação - e o sistema educacional -, assim como as relações sob as quais se estruturam e se desenvolvem, estão susceptíveis aos preceitos da luta dos contrários. Assim sendo, também a educação pode apontar perspectivas não meramente reprodutivistas, pois ela se processa na História e esta é um campo aberto de possibilidades. Apostamos na análise de Althusser (1996) acerca dos Aparelhos Ideológicos de Estado (AIE), não concebendo a educação como uma instituição cristalizada - que paira acima e além da luta de classes. Ela (a educação) é um dos canais 
de reprodução ideológica - essencialmente fundada nas relações materiais - da lógica capitalista e, assim como a própria ideologia, não pode prescindir da objetividade das relações sobre as quais se produzem/reproduzem (também na forma memória). Nesse sentido, é possível invalidar o padrão estruturante da racionalidade reprodutivista imposto pelo sistema capitalista à educação, rompendo a relação cristalizada entre trabalho alienado (desvinculado dos meios de produção/capital e do seu produto) e educação alienante (vinculada ao trabalho alienado), o que implica rompimento das relações sociais de produção capitalistas.

Fruto de uma dinâmica social marcada pela contradição, tanto a educação quanto a ideologia - esta como um mero campo do domínio das ideias dominantes, perpassadas por diversos aparelhos ideológicos - sofrem os reveses das transformações imprimidas pela luta dos contrários. As ideias dominantes (e as suas memórias) são fruto do resultado, sempre parcial (posto que dinâmico, dialético), da luta de classes. Juntamente com Pêcheux (1996), questionamos a concepção reducionista que restringe o campo da ideologia à mera reprodução das ideias das classes dominantes. Assim, tanto a educação, como a ideologia que a perpassa e perpassa as memórias, são resultado da luta social intestina que se processa no âmbito da luta de classes. Mais, não são elas os únicos elementos que definem a reprodução das relações de produção.

Em qualquer forma de sociabilidade, a ideologia tem sua existência pautada na materialidade da vida (Marx, 2007), não é produto meramente teórico, abstrato, tendo como pontos de partida e chegada a pratica social, cabendo-lhe um papel sociopolítico. A ideologia não é fruto da sociedade capitalista, mas, nesta, cumpre o papel específico de conformar a luta de classes a partir de uma visão distorcida da realidade. Sua objetivação se dá nas práticas sociais e toma forma no discurso. Neste campo, a ideologia se processa de forma a dar consistência às relações sociais de produção, contribuindo na sua reprodução, propagando ideias, significados e valores que confundem mais que esclarecem. No "domínio da memória" (Courtine, 1981), o discurso legitima a exploração do trabalho em detrimento da produção de uma riqueza social socialmente distribuída. Em Pêcheux (1988), a memória discursiva legitima a existência histórica dos enunciados relativos às expressões concretas, materiais, da ideologia em movimento. Isto é, memória subsistente (aquilo que sobrevive do passado no presente, sentido de preservação e reprodução da sociedade).

Se, em Ricceur (2007), memória e esquecimento são categorias inseparáveis, para nós a relação não só é inseparável, mas susceptível à interferência da ideologia. Esquecer ou lembrar pode significar atos inerentes ao processo de dominação político-econômica. Ambos produzem, nos sujeitos sociais, um efeito de ocultação daquilo que precisa ser lembrado, memorizado, rememorado, festejado e daquilo que deve ser olvidado para o bem de uma dada ordem. Esquecer ou lembrar algo contribui para alimentar um projeto e sepultar outro, mesmo levando em conta o que afirmava Marx quando dizia que superar a condição de exploração "é um ato histórico, não um ato mental" (1986, p. 65). Diferentemente do propugnado pelo discurso hegemônico, tal superação só pode dar-se por vias reais, concretas.

O significado estruturante da educação e sua relação com o trabalho não nos permite pensá-la fora dessa mesma lógica. O termo educação, em seu sentido geral, denota a difusão, o aperfeiçoamento e o aprendizado de técnicas produzidas por homens e mulheres através do trabalho, com o objetivo de atender a necessidades individuais e coletivas. O conjunto dessas técnicas é fundamental para a sobrevivência humana em sociedade, servindo de veículo para que o conhecimento produzido socialmente possa ser transmitido de geração a geração. Assim, a divisão do trabalho é ponto chave para se 
entender as relações entre os homens e a natureza, e aqueles entre si, constituindo-se uma linha primordial por meio da qual podem ser reveladas as categorias históricas que constituem a sociedade capitalista.

Independente do modo de produção, a relação social entre homens e mulheres, compreendida como cooperação entre indivíduos, sob quaisquer condições históricas, está sempre ligada a um determinado modo de cooperação e a uma dada evolução das forças produtivas, em condições determinadas, como no artesanato, na escravidão ou no assalariamento. Sob o capitalismo, essa força produtiva é apropriada privadamente.

A organização social dos homens, em todos os momentos históricos, gera a produção de bens materiais imperiosos à satisfação de suas necessidades. E o conjunto de relações sociais entre os seus semelhantes e os instrumentos necessários à produção/reprodução - relações de produção - constituem-se formas como homens e mulheres desenvolvem seu trabalho, estabelecendo hierarquias no processo de produção/reprodução da vida. Tais relações, em uma sociedade concreta, são determinadas pelo modo como se apropriam e controlam a força de trabalho, os instrumentos, os objetos de trabalho e como controlam e distribuem os produtos gerados pelo processo produtivo. As relações de produção e as forças produtivas são os componentes básicos do modo de produção, base material da sociedade. Marx e Engels explicitaram que os homens seriam semelhantes às aranhas e abelhas se permanecessem na forma originária das suas forças produtivas, tendo o seu desenvolvimento como condição necessária para a existência humana quando afirmou

[...] o pressuposto de que os homens têm de estar em condições de viver para poder "fazer história". Mas, para viver precisa-se, antes de tudo, de comida, bebida, moradia, vestimenta e algumas coisas mais. $\mathrm{O}$ primeiro ato histórico é, pois, a produção dos meios para a satisfação dessas necessidades, a produção da própria vida material, e este é, sem dúvida, um ato histórico, uma condição fundamental de toda a história, que ainda hoje, assim, como há milênios, tem de ser cumprida diariamente, a cada hora, simplesmente para manter os homens vivos (Marx e Engels, 2007, p. 32)

Assim, ao longo do tempo a sociedade foi somando conhecimentos oriundos nas suas práticas sociais, modificando os instrumentos, os objetos e o grau de preparação da força de trabalho, acumulando e transformando as forças produtivas, a começar pelos próprios indivíduos, estes como força produtiva dotada de subjetividade e intencionalidade. É nesse movimento que homens e mulheres vão se educando e sendo educados.

Nesse processo há avanços, retrocessos e interrupções das forças produtivas, que levam a transformações das relações de produção, do modo de produção e das formações sociais. Para viver em sociedade, reproduzi-la ou criar coisas novas, os seres humanos estão em permanente confronto. O nível de desenvolvimento das forças produtivas de uma determinada sociedade depende do avanço e da acumulação de conhecimentos, da força de trabalho e da tecnologia. Porém, nas sociedades marcadas pela divisão de classes, o acesso a esse conhecimento não é disponibilizado a todos. A história mostra que não há uma homogeneidade no conjunto da sociedade humana no que diz respeito à posse dos meios de produção, de conhecimentos técnicos e, consequentemente, da riqueza produzida. $\mathrm{O}$ espelho dessas relações descontínuas e desiguais reflete a divisão social e técnica do trabalho, mostrando que o acesso a experiências educativas passa pelas hierarquias de classe - e, dentro destas, de gênero.

A divisão social do trabalho, acompanhada pela introdução da técnica, fez com que 
aumentasse a produtividade deste, gerando uma produção de excedentes, apropriados privativamente. Esse foi um processo que se deu desde a existência das sociedades primitivas, e a educação o acompanhou. Desde o estágio primitivo, os povos reservavam determinados conhecimentos como privilégios de chefes de tribos, referências que simbolizavam relações de respeito e manifestação de deferências, posteriormente reveladas como sinal de nobreza, o que implica relação de poder. A constituição, manutenção e domínio de certos tipos de conhecimento, simbolizando a propriedade intelectual do conhecimento desempenharia importante papel na consolidação das ideias e interesses das classes proprietárias (Ponce, 2007).

A produção de conhecimento - e a educação - deixava de ser reconhecida e constituída de modo comunitário e passava a ser organizada segundo os interesses de classe e gênero. A apropriação privada dos meios de produção e a exploração do homem pelo próprio homem originaram relações de dominação e submissão e, em consequência, o processo educativo passou a privilégio do grupo dominante de uma determinada formação social. Essas contradições afloraram, ao longo da história, na hierarquia do trabalho, na família - e entre elas - e na desigual distribuição do acesso ao trabalho, o que, no campo da educação, aflorou na imposição de alguns grupos sobre outros de condições de trabalho, e, consequentemente, e os padrões em que devem educar e serem educados.

Assim, entendemos que, para se compreender os fundamentos da simbiótica relação entre trabalho e educação, necessita-se evidenciar a concepção de sociedade na qual esta se encontra orientada. No caso da sociedade atual, a capitalista, esta relação está pautada na lógica da subsunção do trabalho ao capital. Isso entendido porque a subsunção real (e formal) do trabalho ao capital, além de originar-se na base material da sociedade capitalista, estar no seu âmago, apresenta-se como condição inexorável do objetivo maior da lógica acumulativa capitalista que é o acúmulo e expansão do capital. Por fim, de forma geral, é esta relação (subsunção do trabalho ao capital) que estabelece as diversas mediações das relações sociais nas formações sociais capitalistas.

Um dos caminhos para estudarmos essa relação (educação e trabalho), como mostra Lombardi, é a partir dos processos de trabalho que se desenvolveram ao longo da história do capitalismo e, naturalmente, na compreensão da divisão do trabalho, descrita por Marx, desde o período manufatureiro:

[...] a problemática educacional não é tratada em si mesma, mas é parte integrante do quadro teórico fundamental da análise de Marx sobre o processo de subordinação do trabalho ao capital. Dessa perspectiva, pensar historicamente a educação é acompanhar o próprio processo de transformação das relações fundamentais desse modo de produção (2011, p. 107).

As transformações históricas sofridas pelo trabalho nas diferentes formas assumidas pelo capital tiveram como objetivo o aumento da produtividade, num processo em que a separação da concepção e execução daquele (divisão entre trabalho intelectual e manual, entre os que planejam e os que executam), o afastamento de mulheres e homens dos seus meios de produção e a presença da mais-valia são elementos sine qua non de sua existência. E é por meio dessa análise, ou seja, das condições materiais de existência da humanidade, que podemos compreender a educação e seu papel histórico.

A História nos ensina que, ao originar-se a manufatura a partir do artesanato, inicialmente a cooperação simples era formada pela união de trabalhadores de diversos ofícios autônomos, reunidos em uma oficina sob o comando de um mesmo capitalista, por 
cujas mãos passavam um produto até a fase final de sua produção. Posteriormente, a manufatura parte da cooperação de artífices que desenvolvem o mesmo ofício, decompondo-o em diversas operações particulares isoladas, tornando-as autônomas, até o ponto em que cada uma delas se torna uma função exclusiva de um trabalhador específico. Nesse sentido, os trabalhadores perderam "a capacidade de exercer o seu antigo ofício", tornando a sua atividade unilateral, visto que seu trabalho nas oficinas passou a ser decomposto em diversas operações parciais (Marx, 1985, p.267).

Nesse processo, o trabalhador perdeu os meios de produção do seu trabalho para o capitalista, embora a produção ainda dependesse da sua capacidade de artesão e de sua habilidade pessoal. Nessa fase, a unidade técnica ainda era incipiente. A maquinaria era o próprio trabalhador coletivo que possuía "todas as propriedades produtivas no mesmo grau de virtuosidade e, ao mesmo tempo, as despende da maneira mais econômica, empregando todos os seus órgãos, individualizadas em trabalhadores ou grupos de trabalhadores" (Marx, 1985, p.276).

No período manufatureiro, é importante destacar que as diferentes funções desenvolvidas pelos trabalhadores coletivos eram divididas em atividades "simples ou mais complexas". As forças de trabalho individuais tinham diferentes graus de educação, possuindo, por isso, diferenciação em termos salariais. No entanto, nas oficinas, o trabalho era feito por trabalhadores parciais que aprendiam as diferentes operações na produção da mercadoria, adaptando-as às suas habilidades naturais e adquiridas. Tal situação demonstra que o processo de produção, baseado na divisão de trabalho, exige "manejos simples, que qualquer ser humano é capaz de realizar" (Marx, 1985). Consequentemente, surge, no interior do trabalho, nas oficinas, a classe dos trabalhadores não qualificados, aqueles que eram excluídos do artesanato, dando origem, no processo de produção, à separação entre trabalhadores "qualificados" e "não qualificados".

A discussão sobre a divisão do trabalho fez parte das considerações de Adam Smith (1996, p. 65) quando tratava do "aprimoramento das forças produtivas do trabalho" como resultado da especialização. Para ele, a introdução da maquinaria facilitava e abreviava o trabalho, aperfeiçoando a divisão, o que nos permite inferir que a invenção das máquinas na manufatura tem sua origem na divisão do trabalho. Os trabalhadores, no dia-a-dia de seu labor, buscam descobrir métodos "mais fáceis e mais rápidos de executar seu trabalho específico" (ibidem). Para Smith (1996), a criação de novas habilidades individuais, com o aprofundamento da divisão do trabalho, torna os trabalhadores mais qualificados para produzir mais riqueza: o aumento da produtividade do trabalho é determinado pela sua intensificação, ressaltando a importância da sua divisão social como fundamental para a produção de riqueza de uma nação.

$\mathrm{Na}$ historicidade do capitalismo, a divisão do trabalho sofreu profundas transformações com a utilização efetiva da tecnologia e da sua organização e controle. $\mathrm{O}$ avanço das forças produtivas com a racionalização do processo de trabalho desenvolveu métodos de produção que possibilitaram a redução do tempo nela empregado e a ampliação do fornecimento de produtos numa escala ascendente, com maior exploração do tempo do sobretrabalho, consubstanciado na divisão social e técnica do trabalho. Para os trabalhadores não qualificados (operários), "os custos de aprendizagem" do trabalho desaparecem por inteiro e, para os trabalhadores qualificados (artífices), tais custos são reduzidos, se comparados com o labor do artesão, diante da simplificação de seu labor. Ocorre, portanto, uma desvalorização relativa da força de trabalho, implicando uma maior valorização do capital, "pois tudo que reduz o tempo de trabalho necessário para reproduzir a força de trabalho amplia os domínios do mais-trabalho" (Marx, 1985, p.276). 
Assim, para entender o processo de produção de mercadorias, base da sociedade capitalista, Marx (1985, pp.277-284) buscou explicar a relação entre a divisão manufatureira e social do trabalho. Tal divisão, no interior da sociedade capitalista, é caracterizada pelo intercâmbio entre os diferentes produtores, mediada pela compra e venda de mercadorias produzidas nas manufaturas pelo conjunto de trabalhadores parciais. $\mathrm{O}$ fracionamento dos meios de produção leva os produtores independentes de mercadorias a se confrontarem, pois "não reconhecem nenhuma outra autoridade senão a da concorrência" (Marx, 1985, p.280). A coerção gerada pela pressão dos diferentes capitalistas em função da concorrência, com o propósito de acumulação do capital, leva os proprietários a buscar meios de produzir mais mercadorias, com menor custo, com o mesmo número de trabalhadores e diminuição de seu valor mediante mudanças nos processos de trabalho.

Tal conclusão sobre o uso de diferentes processos de trabalho com o objetivo de racionalizar a força de trabalho já indica a preocupação dos empregadores em criar métodos de controle sobre ele. A divisão manufatureira do trabalho caracteriza-se pela reunião de um grupo de trabalhadores parciais: cada trabalhador é responsável pelo desenvolvimento de uma operação na produção de uma determinada mercadoria. $\mathrm{O}$ processo de trabalho é dividido em operações parciais, e a concentração dos meios de produção fica nas mãos de um capitalista. A relação de poder que se estabelece entre o capitalista e o trabalhador é mediada pelo controle do processo de trabalho.

Assim, observa-se que, progressivamente, com o desenvolvimento dos procedimentos da produção capitalista, o processo de trabalho passou a ser fragmentado, desde a divisão baseada na cooperação no período manufatureiro de meados do século XVI até o último terço do século XVIII (Marx, 1985). As tarefas passaram a ser combinadas. A reunião de um maior número de trabalhadores, em um só tempo, num mesmo local, sob o controle do capital, desenvolveu um saber decomposto em várias partes simultaneamente. Vários trabalhadores passaram a produzir uma mesma espécie de mercadoria com ações repetidas, tornando-se trabalhadores parciais. Estabelece-se, portanto, uma ruptura entre as funções de concepção e execução, separando os que planejam e decidem dos que executam.

Qual o significado da educação e do trabalho nesse processo? Sobre os termos Educação e Trabalho, sob as relações capitalistas, há tempos se sabe que se interrelacionam. Mais: nutrem uma relação simbiótica, inseparável, indissociada e indissociável. A força de trabalho, uma vez alienada, é tornada mercadoria, atendendo à lógica mais geral do sistema. A educação não foge à regra. Ao mesmo tempo em que serve à produção/reprodução sistêmica ao qualificar/reproduzir força de trabalho, formando recursos para a produção industrial, torna-se, também, um produto a ser consumido por quem demonstra vontade e tem poder aquisitivo para adquirir. E, se é verdade que o trabalho é a base da existência humana - e cremos que sim -, pela forma em que ele se processa no modo capitalista de produção, é absorvido como base da acumulação internacional de capital. É nesse processo que emerge e se eterniza a contradição central do sistema do capital, quer dizer, a existência de uma produção social da riqueza e sua apropriação privada.

A partir daí, se constitui e consolida-se a desigualdade social. Este é o ponto de partida e chegada aqui tomado para se buscar entender a simbiótica relação trabalho/educação na sociedade do capital. Fruto de uma desigual relação entre capital/trabalho, verifica-se, no capitalismo, a apropriação deste último como meio de valorização do capital (Marx, 1984, p. 191), fator realizado com a extração de mais-valia. Numa sociedade permeada pela lógica (acumulativa) de capital, a relação 
trabalho/educação, forçosamente, reproduz essa coerência geral. Incoerente seria se assim não fosse, por tratar-se de um sistema. Em outras palavras, palavras de Marx, a classe trabalhadora "criou um aumento embriagador de riqueza e poder para as classes proprietárias" (1984, p. 216). Isso desde a formação do Estado Nacional burguês, quando o ideário moderno de educação vinculava-a a um comprometimento com os conhecimentos historicamente acumulados sob a luz da razão, razão esta implicada na racionalidade permeante de toda a modernidade, lócus em que se constituem e desenvolvem as relações capitalistas. Nesse sentido, falar de modernidade sugere ter em testemunho o sistema capitalista e todas as suas implicações, imersas na contradição sistêmica central, imprescindível à sua existência: a relação capital/trabalho, e, nesse contexto, a educação, por ser produzida/reproduzida num ambiente de contradições materiais; e memória/ideologia por serem pressupostos de sua reprodução.

Nesse sentido, as principais características do conhecimento científico moderno e, nesse mesmo encalço, a educação - que passou por um necessário processo de formalização, para atender à sociedade industrial - a técnica e a ciência, enfim, o fazer científico, tiveram que obedecer à lógica mercantil, num mundo no qual a acumulação de capital permeia, contundentemente, todas as relações sociais. Por fim, o conceito de ciência e técnica - e, por extensão, Educação - modernos, fazem referência a uma "racionalidade" inerente às relações capitalistas e do modo de acumulação idem. $\mathrm{O}$ que vale dizer: busca aplicar tecnologias de forma manipulada como estratégia adequada aos processos de acumulação de capital.

\section{Referências}

ALTHUSSER, Louis. Ideologia e aparelhos ideológicos de Estado (notas para uma investigação). In: ZIZEK, Slavoj (org). Um mapa da ideologia. Rio de Janeiro: Contraponto, 1996.

COURTINE, Jean-Jacques. Quelques problèmes théoriques et méthodologiques em analyse du discours: à propos du discours communiste adresse aux chrétiens. In Langages, n. 62, Paris: Larousse, 1981, p.9-127.

LOMBARDI, J.C. Educação e Ensino na obra de Marx e Engels. Campinas, SP: Alínea, 2011.

MANACORDA, Mario Alighiero. Marx e a pedagogia moderna. Tradução de Newton Ramos-de-Oliveira. Campinas, SP: Editora Alínea, 2007.

MARX, Karl. O Capital - Crítica da economia política. Livro Primeiro, Tomo 1. São Paulo: Abril Cultural, 1983.

O Capital - Crítica da economia política. Livro Primeiro, Tomo 2. São Paulo: Abril Cultural, 1984.

O Capital - Crítica da Economia Política. In: Coleção "Os economistas", v. 1. 2 ed. Tradução de Regis Barbosa e Flávio R. Kothe. São Paulo: Nova Cultural, 1985.

MARX, Karl; ENGELS, F. A ideologia alemã. Tradução de R. Enderle, N. Schneider e L.C. Martorano. São Paulo: Boitempo, 2007.

MÉSZÁROS, István. A educação para além do capital. $2^{\mathrm{a}}$ ed. São Paulo: Boitempo Editorial, 2008. 
PÊCHEUX, Michel. Semântica e Discurso - Uma crítica à afirmação do óbvio. Campinas: Editora da UNICAMP, 1988.

. Os mecanismos do (des) conhecimento ideológico. In: ZIZEK, S. (Org.) Um mapa da ideologia. Rio de Janeiro, Contraponto, 1996.

PONCE, Anibal. Educação e luta de classes. 22. ed. Tradução de José Severo de Camargo Pereira. São Paulo: Cortez, 2007.

RICCEUR, Paul. A memória, a história, o esquecimento. Campinas: Editora da Unicamp, 2007.

SADER, E. Prefácio. In: MÉSZÁROS, István. Para além do capital. Tradução de Paulo César Castanheira e Sérgio Lessa. São Paulo: Boitempo Editorial, 2005. p. 15-18.

SAVIANI, D. Sobre a Natureza e Especificidade da Educação. In: Pedagogia Histórico-Crítica: primeiras aproximações. 8.ed. Campinas, SP: Autores Associados, 2003.

Trabalho e educação: fundamentos ontológicos e históricos. Revista Brasileira de Educação. V. 12, n. ${ }^{\circ}$ 34. São Paulo: ANPED. V., Jan/ Abr. 2007.

SMITH, A. A divisão do trabalho. In: A riqueza das nações. Coleção os Economistas. Tradução de Luiz João Baraúna. São Paulo: Nova Cultural, 1996.

\section{Notas}

\footnotetext{
* Docente da Universidade Estadual do Sudoeste da Bahia; doutor em Ciências Sociais pela Pontifícia Universidade Católica de São Paulo (PUCSP), com pós-doutoramento em economia política pela Universidade Nacional autônoma do México (UNAM); coordenador do Grupo de Estudos de Ideologia e Lutas de Classes/Museu Pedagógico/UESB; e pesquisador do Núcleo de Estudos de Ideologia e Lutas Sociais (NEILS/PUCSP).

** Docente da Universidade Estadual do Sudoeste da Bahia; doutora em Educação pela Universidade Federal da Bahia; coordenadora do Grupo de Estudos História, Trabalho e Educação/Museu Pedagógico/UESB.
}

Recebido: fevereiro-16 $\quad$ Aprovado: março-16 